\title{
The analyses of definite profitable power of the city web transformer
}

\author{
A $G$ Saidkhodjaev ${ }^{1}, V K \operatorname{Vanin}^{2}$, Najimatdinov $R K^{4}, S H$ Dustova $^{3}$, A Nishanov $^{1}$ \\ ${ }^{1}$ Tashkent state technical university named after Islam Karimov, Tashkent, Uzbekistan \\ ${ }^{2}$ Peter the Great St. Petersburg Polytechnic University \\ ${ }^{3}$ Bukhara branch of Tashkent institute of irrigation and agricultural mechanization, Bukhara, Uzbekistan \\ ${ }^{4}$ Karakalpak State University
}

\begin{abstract}
It gives the analyse of offered metodics of detinite profitable power of the transformer stations (TS) and the colculation formuls received in building standarts and rules (B.S.K 2.04.17-98). The offered new metodics.
\end{abstract}

\section{Introduction}

An important condition for the rational construction of the power supply system of cities is the correct choice of the power of transformer stations (TP), since the cost of the low voltage network and the transformer substations themselves depends on this. So, for example, an overestimation of the capacity of a transformer substation leads to an increase in the length of the lowvoltage network and the cost of building a network, and an underestimation of it increases capital investments for the construction of a transformer substation. Typically, the choice of the optimal substation capacity is made by comparing several options. The application of variant calculations for urban electric networks is difficult, since the number of variants can be very large. Therefore, to facilitate the selection of the optimal power of TP in urban networks, various calculation formulas are proposed, the analysis of which shows that they proceed from the method of calculating wire cross-sections according to the permissible current density of the emergency mode of network operation $\left(\mathrm{F}_{2}\right)$, by permissible voltage loss $\left(\mathrm{F}_{1}\right)$, or from the method of choosing the economically most advantageous section $\left(\mathrm{F}_{4}\right)$ wires.

Another group of formulas proceeds from the method for determining the rational number of transformer substations when calculating the network based on the load current density of the emergency mode, presented in the form of a cubic equation for the specific linear length of the network, and currently the formula is used in design organizations, which V.A. Kozlov has transformed into a convenient form of the cubic equation for the specific load density on the area of the network area [1-5].

Thus, the question of the methodology for choosing the optimal power of TP and the legality of this or that formula has not yet been finally resolved and is debatable. In addition, all formulas were derived for cables with copper conductors and when performing TP in brick rooms. The indicated calculation formulas are based on the analysis of the dependence of the investments made in the construction of the network and network transformer substations on a number of different factors: network voltage, estimated voltage loss, load density, configuration of city quarters, etc.

For the conditions of the urban network in the Republic of Uzbekistan, which has its own characteristics, for example, such as the majority of 6-10 kV transformer substations of a metal structure, wires and cables mainly with aluminum conductors, the ambient temperature and temperature inside the transformer substation are much higher than the normative ones, the specific load density by " ha "in different cities differ sharply from each other. In order to identify the most legitimate formulas for choosing the optimal power of TP, we will analyze various methods in relation to the modern conditions of networks.

For example, we will sequentially consider the formulas for the optimal power [5-9]:

1) "Three authors";

2) B. L. Eisenberg;

3) B.L. Aisenberg and N.I. Medvedsky;

4) P.F. Gogichaishvili;

5) V.A. Kozlova.

The formula of the "Three Authors" (SN Nikogosov, BL Aizenberg, MN Karasik) is based on determining the cross-section of wires or cables by the permissible voltage loss $\left(F_{1}\right)$ developed using the principle of attributing all costs to $1 \mathrm{~m}$ of low voltage network. This formula for any network configuration looks like this:

$$
\mathrm{S}_{\mathrm{T}}=\psi \cdot \sqrt[3]{\frac{a_{i} \cdot \delta^{2} \cdot U \cdot \Delta U \cdot j}{25000 \cdot b_{2}}}
$$

Where: 
$\Psi$ - network configuration factor.

$\mathrm{a}_{\mathrm{i}}$ - part of the cost of transformer substation, which does not depend on the power of the transformer.

$\mathrm{b}_{2}$ - part of the cost, depending on the cross-section of the wires.

$\mathrm{U} ; \Delta \mathrm{U}$ - line voltages and losses

$\mathrm{j}$ - the cost of one $\mathrm{kW}$ of electricity per year.

B.L. Eisenberg proposed a formula for the case of choosing the wire cross-section of a low voltage network $\left(\mathrm{F}_{2}\right)$ according to the permissible current density, load of the emergency operation of the network:

$$
\mathrm{S}_{\mathrm{T}}=\sqrt[3]{\frac{a_{i} \cdot \delta \cdot U^{2} \cdot n^{2}}{3660 \cdot b_{2}}}
$$

To be unattainable to compare these formulas, they were brought to form [10-13].

$$
\begin{aligned}
& \mathrm{ST}_{\mathrm{T}}=f(\delta) \\
& \mathrm{S}_{\mathrm{T}}=K_{1} \sqrt[3]{\delta^{2}} \\
& \mathrm{~S}_{\mathrm{T}}=K_{2} \sqrt[3]{\delta} \\
& \mathrm{n}=2-3 \\
& K_{1} \text { and } K_{2} \text {-coefficients depending on different conditions. }
\end{aligned}
$$

For areas of new development, where the determination of capacity may be difficult B. L. Aisenberg and N. I. Medvedsky proposed a formula.

$$
\mathrm{S}_{\mathrm{T}}=K_{3} \sqrt[3]{\delta^{2}} \quad \text { or } \mathrm{S}_{\mathrm{T}}=K_{4} \sqrt[3]{\delta}
$$

The method proposed by V.A. Kozlov for determining the rational power of TP differs from other methods in that to determine the optimal value $S_{T}$ the formula additionally introduces the costs of the high voltage distribution network. In addition, this method is not based on determining the cross-section of the wires according to $F_{1}$ by permissible voltage loss or $\mathrm{F}_{2}$, by the permissible current density, and by determining the optimal cross-section $\mathrm{F}_{0}$.

The formula looks like this: [14-20].

$$
\mathrm{S}_{\mathrm{T}}=\sqrt{\frac{\left(C_{01}+B\right) \cdot D \cdot m \cdot U}{3,8 \cdot \sqrt{c \cdot \tau \cdot c}} m}=\mathrm{S}_{\mathrm{T}}=K_{5} \sqrt[3]{\sigma}
$$

Where

$\mathrm{C}_{01}$ - part of the annual costs of TP, independent of the power of transformers

$\mathrm{c}_{\mathrm{m}}$ - cost of $1 \mathrm{kWh}$ of electricity losses

$\tau$-annual number time of maximum losses

c - part of the annual costs for the low voltage network.

$\mathrm{B}$ - annual costs for the medium voltage network (above $1000 \mathrm{~V}$ )

$\mathrm{m}$ - the number of low voltage main lines outgoing from the TP.

D - annual costs for the low voltage network $(0.38 \mathrm{kV})$.

Experimental data showed that according to the formula of V.A. Kozlov, the optimal power of the transformers increases, and the optimal cross-section of the cable Fo decreases.

In the work of P.F. Gogichaishvili the formula for the optimal power of the network transformer substation is derived for the case of determining the wire cross-sections of the urban network of $0.38 \mathrm{kV}$ by the economic current density. Just like V.A.Kozlov, P.F. Gogichaishvili introduces into his formula the cost of electricity losses in the network. P.F. Gogichaishvili's formula looks like this:

$$
\mathrm{S}_{\mathrm{T}}=0,65 \cdot \sqrt{\frac{\left(\delta_{\mathrm{T}} K_{\mathrm{T}}+C_{\mathrm{T}}\right) \cdot D \cdot U \cdot m \cdot \sqrt{\gamma}}{\sqrt{\delta_{\mathrm{H}} \cdot \mathrm{K}_{\mathrm{H}} \cdot \eta^{\prime} \cdot \mathrm{C} \cdot \tau}}}=K_{7} \sqrt{\delta}
$$

This formula cannot be used to determine ST (optimal power of TP), since it is derived from the condition for choosing the cross-section of wires and cables by economic current density (F4), and is intended for single-storey buildings with low load density, but it is known that there are many publications and it has been proven that the calculation of the city power grid by the economic load density gives overestimated results and is not used in low-voltage networks.

The author proposes to calculate the determination of the rational power of TP based on the load density per hectare of the microdistrict area, taking into account the additional costs of the high voltage distribution network and the cost of electricity losses in the network, as well as on the basis of the experimentally developed full set of characteristic (typical) daily electric load schedules all consumers included in this network. For this, 48 - 24 options are calculated for each half-hour or hourly time interval and the largest maximum optimal option for calculating the network is determined. We have improved the method for determining the rational power of transformers in urban electrical networks. The proposed formula is based on the formula of V.A. Kozlov, which takes into account the losses on the low and high side of the voltage, as a part of the additional annual costs depending on the section. According to the formula (7), for a load density up to $40 \mathrm{~kW} / g a$, and at a load density equal to or more than $40 \mathrm{~kW}$ per hectare, the power of the TP is determined by the formula (8):

$$
\begin{gathered}
P_{\mathrm{T}}=\sqrt{\frac{\left(C_{01}+B\right) D m U}{3,8{\sqrt{c_{H} \cdot c_{B} \cdot \tau \cdot c}}_{m}}}=\quad \mathrm{P}_{\mathrm{T}}=K_{7} \sqrt[3]{\sigma^{2}} \\
\mathrm{P}_{\mathrm{T}}=K_{8} \sqrt[3]{\sigma}
\end{gathered}
$$

where $K_{7}=20, a K_{8}=50$;

$\mathrm{c}_{\mathrm{m}}$ - cost of $1 \mathrm{kWh}$ of electricity losses;

$\tau$ - annual number of time of maximum losses;

$\mathrm{c}_{\mathrm{HH}}$ - part of annual costs, taking into account losses in the low voltage network, depending on the cross section;

$\mathrm{C}_{\mathrm{BH}}$ - part of annual costs, taking into account losses in the high voltage network, depending on the cross section;

B - annual expenses on the high voltage network;

D-the population of the microdistrict;

$\mathrm{m}$ - the number of low voltage main lines outgoing from the TP.

Formulas (7) and (8) are recommended for micro-districts of the residential zone of cities. Based on the number of transformer substations in the microdistrict, the required capacity of each substation is determined. For this, the TP in the amount specified above are placed on the plan of the microdistrict. Then the actual design load for each transformer substation is determined, after which the required installed capacity of each substation is found.

At the present stage, a more accurate determination of the rational capacity of the TP of the city network for different load densities on the building area of the residential zone of cities (ha) can be calculated on the basis of the probabilistic-statistical method, using typical daily schedules of consumers powered by TP, taking into account losses in the networks 0 , 38 and $6-10 \mathrm{kV}$. To take into account losses in the network and the optimal cross-section, it is necessary to take the first and second derivatives 
of the initial parameters of the microdistrict power supply system and calculate the optimal power of the TP [21-22].

\section{Conclusions}

1. The rational power of TP is determined by the load density per 1 hectare of the area of the microdistrict according to the formula (7), for a load density equal to or more than $40 \mathrm{~kW}$ per hectare, and at a load density of up to $40 \mathrm{~kW}$ per hectare, the rational power of the TP is determined by the formula (8).

Where $K_{7}=20$, a $K_{8}=50$. Formulas (7) and (8) recommended for areas with multi-storey buildings, adopted in building codes and regulations (KMK 2.04.17 - 98 "Electrical equipment of residential and public buildings" Tashkent "Uzgoskomarkhitektstroy". 1998.) [23-24].

2. Based on the number of transformer substations in the microdistrict, the required capacity of each substation is determined. For this, TPs are placed on the plan of the microdistrict. Then the actual design load for each transformer substation is determined. The calculation must be carried out 24 - 48 options summing up all the daily load schedules included in the consumer's TP for each half hour or hour of the day and the maximum load from these options will be the calculated total load for this TP. After that, the required installed capacity of each substation is found according to the formula:

$$
\mathrm{S}_{\text {уст.п. }}=\frac{\mathrm{P}_{\text {расч }}}{1,4 \cdot \operatorname{Cos} \varphi} \quad \mathrm{\kappa BA}
$$

where

$\cos \varphi$ - the weighted average power factor for the sum of the consumer load feeders outgoing from the TP, is usually taken equal to 0.9 for urban networks.

1, 4 - coefficient taking into account the permissible load of transformers at maximum loads due to the load during operation during the period of minimum loads.

$\mathrm{P}_{\text {pacy }}$ - total design load on this transformer substation, $\mathrm{kW}$

3. At the present stage, a more accurate determination of the rational capacity of the TP of the urban network for different load densities on the area (ha) of development of the residential zone of cities can be calculated on the basis of the method using the developed standard (characteristic) schedules of consumers powered by TP.

For an urban network, starting with buildings and structures, the calculation of the cross-sections of wires and cables $(0.38 \mathrm{kV})$ must be carried out according to the method of long-term allowable current, by heating, with checking the cross-section for the allowable voltage loss and no matter the time taken as the calculated maximum $(15,30,60 \mathrm{~min})$, and what is important is the maximum current of the total load of the TS, found from the typical (characteristic) daily graphs.

To take into account losses in the network and the optimal crosssection, it is necessary to take the first and second derivatives of the initial parameters of the power supply system of the microdistrict and calculate the rational, (extremum) power of the TP.

\section{References}

1. BL Aizenberg, NV Volotskaya et al. City electrical networks. "GEI", M., L.: 1958. - 325 p.

2. Kozlov V.A. and other Handbook on the design of power supply of cities. L .: Energoatomizdat. 1986 .- 256p.

3. Construction norms and rules KMK 2.04.17 - 98 "Electrical equipment of residential and public buildings" Tashkent "Uzgoskomarkhitektstroy". 1998 .-- 145 p.

4. I.Rakhmonov, A.Berdishev, N.Niyozov, A.Muratov and U.Khaliknazarov. Development of a scheme for generating the predicted value of specific electricity consumption // CONMECHYDRO - 2020. IOP Conf. Series: Materials Science and Engineering. $883 \quad$ (2020) 012103. doi:10.1088/1757-899X/883/1/012103

5. F.A.Hoshimov, I.I.Bakhadirov, M.S.Kurbanbayeva, N.A.Aytbayev. Development of specific standards of energy consumption by types of produced products of the spinning product // RSES 2020. E3S Web of Conferences. 216 (2020) 01169. https://doi.org/10.1051/e3sconf/202021601169

6. F.A.Hoshimov, I.I.Bakhadirov, A.A.Alimov, M.T.Erejepov. Forecasting the electric consumption of objects using artificial neural networks // E3S Web of Conferences. $216 \quad$ (2020) 01170. https://doi.org/10.1051/e3sconf/202021601170

7. I.U.Rakhmonov, F.A.Hoshimov. Development of an algorithm for evaluating the dominant factors that have the greatest impact on the energy intensity of products // ENERGY-21. E3S Web of Conferences. 209 (2020) 07018. https://doi.org/10.1051/e3sconf/202020907018

8. Usmanov E.G. Stability in a parallel resonant circuit with active load // RSES 2020. E3S Web of Conferences. 216 (2020) 01160. https://doi.org/10.1051/e3sconf/202021601160 9. Usmanov E.G., Khusanov B.M. Phase relations in resonant circuits with a wide falling section on the amplitude characteristic // RSES 2020. E3S Web of Conferences. 216 (2020) 01161. https://doi.org/10.1051/e3sconf/202021601161 10. I.U.Rakhmonov, K.M.Reymov. Statistical models of renewable energy intermittency // RSES 2020. E3S Web of $\begin{array}{llll}\text { Conferences. } & 216 & \text { (2020) } & 01167 .\end{array}$ https://doi.org/10.1051/e3sconf/202021601167

11. I.U.Rakhmonov, N.N.Kurbonov. Analysis of automated software for monitoring energy consumption and efficiency of industrial enterprises // E3S Web of Conferences. 216 (2020) 01178. https://doi.org/10.1051/e3sconf/202021601178

12. F.A.Hoshimov, I.U.Rakhmonov, N.N.Niyozov. Technology to reduce energy costs in the electric steel melting shop // ENERGY-21. E3S Web of Conferences. 209 (2020) 07017. https://doi.org/10.1051/e3sconf/202020907017

13. A.Taslimov, F.Rakhimov, L.Nematov, N.Markaev, A.Bijanov, R.Yunusov. Economic load intervals for selecting $10 \mathrm{kV}$ cable cross-sections for agricultural consumers // CONMECHYDRO - 2020. IOP Conf. Series: Materials Science and Engineering. $883 \quad$ (2020) 012102. doi:10.1088/1757-899X/883/1/012102

14. A.Taslimov, M.Melikuziev, O.Matchonov, M.Ruzinazarov and M.Nasirov. Development of standard cable cross-sections of rural electrical networks // CONMECHYDRO - 2020. IOP Conf. Series: Materials Science and Engineering. $883 \quad$ (2020) 012105. doi:10.1088/1757-899X/883/1/012105

15. I.Bakhadirov, N.Markaev, G.Aslanova, R.Tanatarov, S.Makhmuthonov. Differentiated tariffs of electricity for the 
improvement of steelmaking Uzbekistan // CONMECHYDRO - 2020. IOP Conf. Series: Materials Science and Engineering. $883 \quad$ (2020) 012121. doi:10.1088/1757-899X/883/1/012121

16. A.D.Taslimov, A.S.Berdishev, F.M.Rakhimov and A.A.Yuldashev. Optimal tendency of selecting cable crosssections for agricultural electrical networks // ICMSIT-2020. Journal of Physics: Conference Series. 1515 (2020) 022056. doi:10.1088/1742-6596/1515/2/022056

17. Abduraxim Berdishev, Abdurakhim Taslimov, Bakhtiyor Melikuziev and Alibi Bijanov. Reliability indicators of $10 \mathrm{kV}$ cable lines in rural areas // FORM-2020. IOP Conf. Series: Materials Science and Engineering. 869 (2020) 011001. doi:10.1088/1757-899X/869/1/011001

18. A.D.Taslimov. Selection of a complex of parameters of distribution electric networks with respect to technical limitations // ENERGY-21. E3S Web of Conferences. 209 (2020) 07013. https://doi.org/10.1051/e3sconf/202020907013 19. A.D.Taslimov, F.M.Rakhimov, A.O.Norkulov, A.A.Yuldashev. Research of the optimum scale of standard sections of agricultural purpose lines // E3S Web of $\begin{array}{llll}\text { Conferences. } & 216 & \text { (2020) } & 01158 .\end{array}$ https://doi.org/10.1051/e3sconf/202021601158

20. A.D.Taslimov., M.V.Melikuziev, A.M.Najimova, A.A.Alimov. Economic load intervals for selection of cable sections for agricultural purpose // E3S Web of Conferences. 216 (2020)

01159.

https://doi.org/10.1051/e3sconf/202021601159

21. Olimjon Toirov, Tulyagan Kamalov, Utkir Mirkhonov, Sardor Urokov, Dilnoza Jumaeva The mathematical model and a block diagram of a synchronous motor compressor unit with a system of automatic control of the excitation, E3S Web of Conferences, SUSE-2021 (2021)

22. Baratov B., Toshov J., Baynazov U. Method of calculating the gear ratios of the cones of tricone drill bits // E3S Web Conf., Volume 201, 01012, 2020, Ukrainian School of Mining Engineering - 2020. https://doi.org/10.1051/e3sconf/202020101012

23. Haqberdiev A., Toshov J. Analysis of the control system of electric motors of the running gear of self-propelled mine cars used in complex mining and technological conditions // E3S Web of Conferences 216, 01135 (2020), Rudenko International Conference "Methodological problems in reliability study of large energy systems" (RSES 2020), https://doi.org/10.1051/e3sconf/202021601135

24. Karimov R.Ch., Bobojanov M.K., Rasulov A.N., Usmanov E.G. Controlled switching circuits based on nonlinear resistive elements (E3S Web of Conferences, 139, 01039, 2019), https://doi.org/10.1051/e3sconf/201913901039 